\title{
CORRIGENDUM
}

\section{The deubiquitylase USP37 links REST to the control of p27 stability and cell proliferation}

CM Das, P Taylor, M Gireud, A Singh, D Lee, G Fuller, L Ji, J Fangusaro, V Rajaram, S Goldman, C Eberhart and V Gopalakrishnan

Oncogene (2016) 35, 6153-6154; doi:10.1038/onc.2016.141; published online 18 July 2016

Correction to: Oncogene (2012) 32, 1691-1701; doi: 10.1038/ onc.2012.182; published online 4 June 2012

The authors were recently made aware of a concern regarding an irregularity in Figure $5 \mathrm{~d}$ of this publication. The loading control for Figure 5d was inserted incorrectly. Although assembled correctly in the original file, it was transposed when generating a final file. Please see the corrected Figure 5; revised panel $5 d$ includes the correct loading control.

The authors apologize for any inconvenience caused by this error. 
a

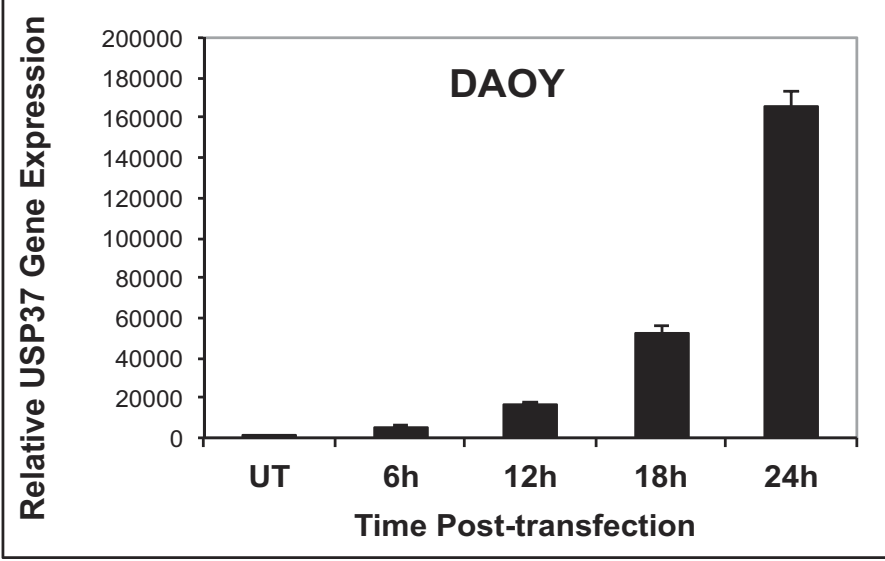

b

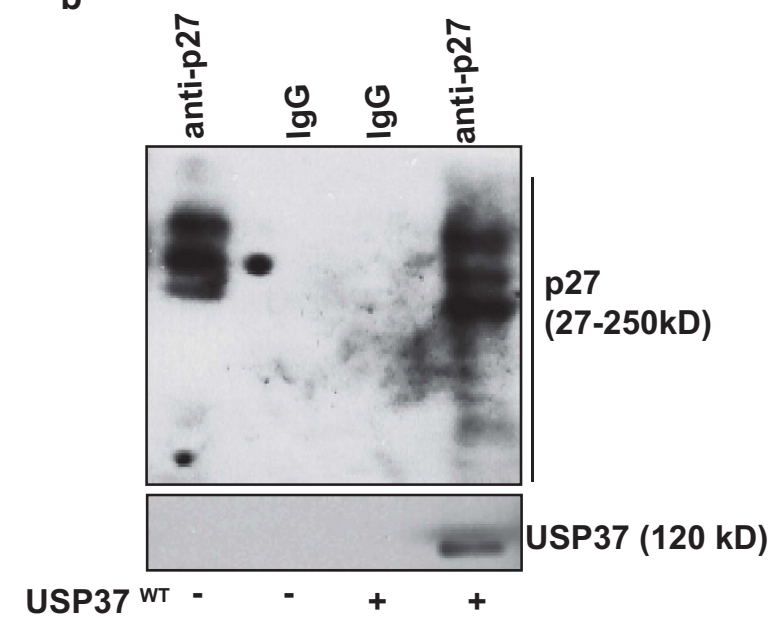

C

$\begin{array}{lllll}\text { Time (H) } \quad \text { UT } & 6 \quad 12 \quad 18\end{array}$

FLAG-US37 wT -+++

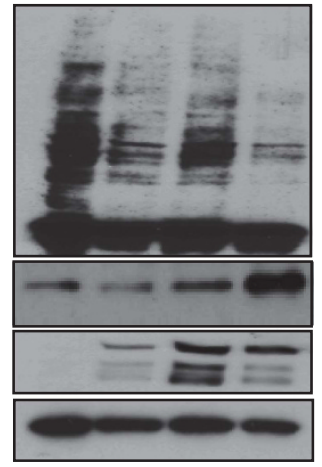

p27

(27-250kD)

p27 (27 kD)

USP37 (120 kD)

GAPDH (35 kD)

d

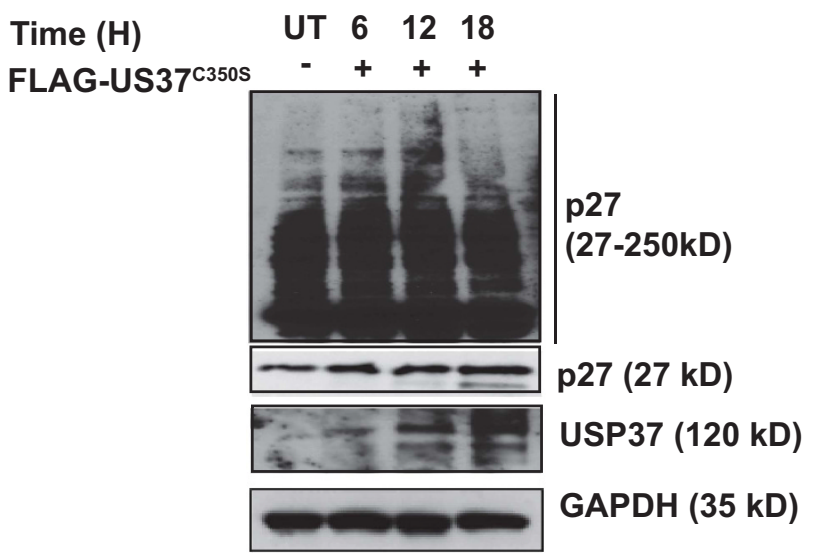

f

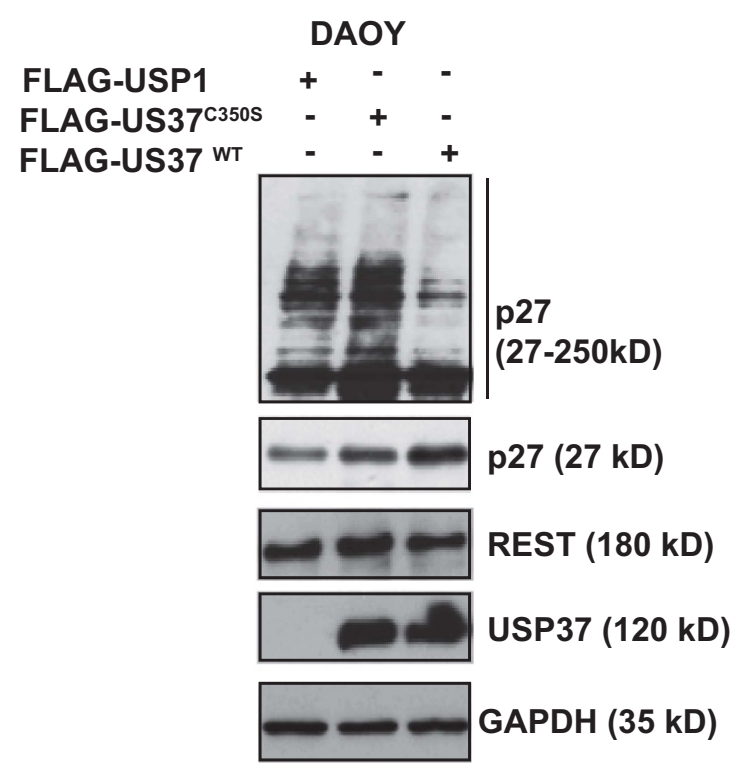

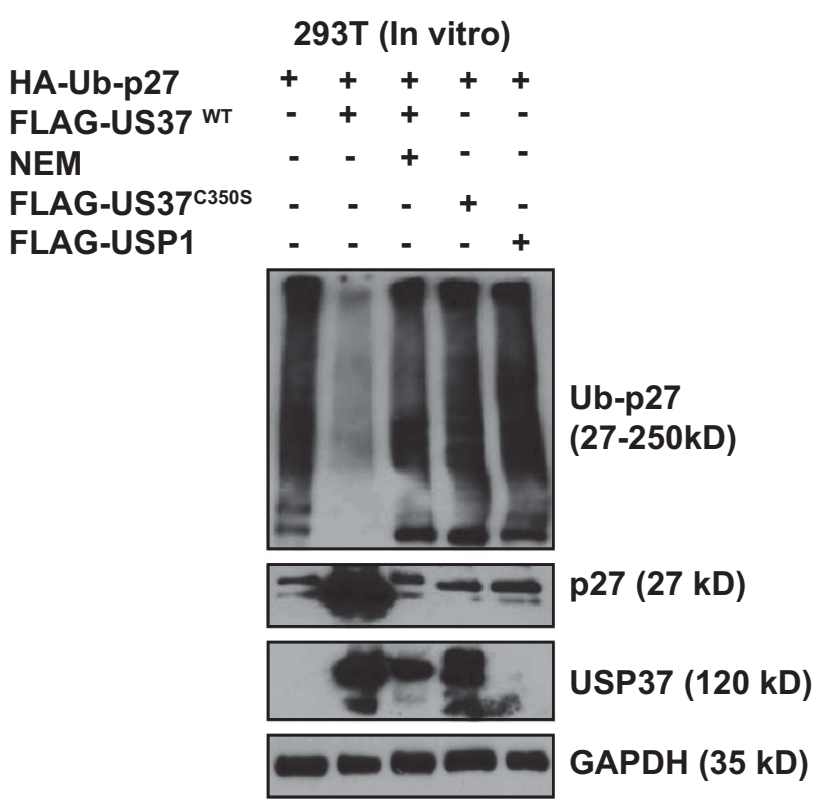

